\title{
MEDIÇÃO DE DESEMPENHO PARA A GESTÃO DO CICLO DE VIDA DE PRODUTOS: UMA REVISÃO SISTEMÁTICA DA LITERATURA
}

\section{PERFORMANCE MEASUREMENT FOR PRODUCT LIFECYCLE MANAGEMENT: A SYSTEMACT LITERATURE REVIEW}

\author{
Fernando Elias Alves da Fonseca* E-mail: ffonseca@sc.usp.br \\ Henrique Rozenfeld* E-mail: roz@sc.usp.br \\ *Universidade de São Paulo, São Carlos, SP
}

\begin{abstract}
Resumo: O objetivo desse trabalho é identificar uma coletânea de recomendações e os principais indicadores de desempenho utilizados para o desenvolvimento de um sistema de medição de desempenho (SMD) para a gestão do ciclo de vida de produto (Product Lifecycle Mangement - PLM). Para tanto, realizou-se uma revisão bibliográfica sistemática que identificou 22 recomendações e 296 indicadores de desempenho.
\end{abstract}

Palavras-chave: Medição de desempenho. Indicadores de desempenho. Gestão do ciclo de vida de produtos.

Abstract: The aim of this study is to identify recommendations as well as the main performance indicator for developing a performance measurement system (PMS) for product lifecycle management (PLM) approach. Thus it was performed a systematic literature review that identified 22 recommendations and 296 performance indicators.

Keyword: Performance measurement. Performance indicator. product lifecycle management.

\section{INTRODUÇÃO}

A gestão do ciclo de vida de produtos ou Product Lifecycle Management (PLM) é uma abordagem que abrange todos os processos de negócio relacionados aos produtos e permite às empresas controlar todas as informações de seus produtos ao longo do ciclo de vida, desde a concepção inicial até o descarte (GRIEVES, 2006; SAAKSVUORI; IMMONEN, 2003; STARK, 2006; ZANCUL, 2009).

Dentre os processos abrangidos pela abordagem PLM, está o processo de desenvolvimento de produtos (PDP) que auxilia a criação de produtos mais competitivos e, dessa forma, permite que as empresas estejam preparadas para as recentes mudanças no ambiente de negócios como a intensificação da concorrência, a redução do ciclo de vida dos produtos, o avanço das tecnologias e a busca constante por produtos de alta qualidade e baixo custo (CHEN; YEH; YANG, 2006; 
DRIVA; PAWAR; MENON, 2000; GODENER; SODERQUIST, 2004; YEH; PAI; YANG, 2010).

Recentemente, esse tema tem chamado a atenção de acadêmicos e profissionais, pois a eficiência e eficácia das atividades dos processos de negócio que compõem o PLM podem determinar o sucesso ou fracasso das empresas e, dessa forma, medir o desempenho de tais atividades pode determinar a sobrevivência das empresas (GODENER; SODERQUIST, 2004; PAWAR; DRIVA, 1999; ROGERS; GHAURI; PAWAR, 2005).

Entretanto, a medição de desempenho para a gestão do ciclo de vida de produtos é uma tarefa difícil e complexa, devido, principalmente, à natureza não estruturada e não repetitiva dos processos de negócio que compõem tal abordagem. Além disso, alguns autores comentam sobre a influência de fatores externos não controláveis que podem afetar o sucesso do projeto e a necessidade de um grande intervalo de tempo para percepção dos resultados (BANWET; DESHMUKH, 2006; CHEN; YEH; YANG, 2006; CHIESA et al., 2008; LOCH; TAPPER, 2002; O'DONNELL; DUFFY, 2002; PILLAI; JOSHI; RAO, 2002; ROGERS; GHAURI; PAWAR, 2005; SANDSTRÖM; TOIVANEN, 2002; TATIKONDA, 2008).

Dessa forma, é importante que no desenvolvimento de um sistema de medição de desempenho (SMD) para a gestão do ciclo de vida de produtos sejam consideradas estas dificuldades e, também, conhecida as principais recomendações para esse desenvolvimento bem como os principais indicadores de desempenho para PLM apresentados na literatura.

Nesse sentido, foi realizada uma revisão bibliográfica sistemática com o objetivo de identificar as principais recomendações para o desenvolvimento de um SMD para PLM e os principais indicadores de desempenho para PLM. Assim, espera-se que estes elementos possam ajudar as empresas a superarem as dificuldades inerentes à medição de desempenho para PLM auxiliando-as no desenvolvimento de um SMD.

\section{GESTÃO DO CICLO DE VIDA DE PRODUTOS}

O ciclo de vida de um produto compreende todas as fases pelas quais os produtos passam, desde a ideia inicial, passando pelo desenvolvimento, produção, 
venda e manutenção, culminando na disposição final do produto (FELDHUSEN; BUNGERT, 2007).

De maneira geral, pode-se considerar que o ciclo de vida apresenta quatro macro-fases principais, visto que na maior parte dos trabalhos que apresentam as fases do ciclo de vida de produtos elas estão sempre presentes, porém, em diferentes níveis de detalhamento. As quatro macro-fases consideradas são: desenvolvimento, produção, uso e descarte (FELDHUSEN; BUNGERT, 2007; MA; FUH, 2008; REBITZER et al., 2004; THIMM; LEE; MA, 2006; XIAO et al., 2009; ZANCUL, 2009).

Para Saaksvuori e Immonen (2003) a gestão do ciclo de vida de produtos é um conceito que abrange a gestão integrada de todas as informações relacionadas ao produto ao longo do seu ciclo de vida.

Grieves (2006) define PLM como uma abordagem integrada orientada a informação composta por pessoas, processos, práticas e tecnologia que abrange todos os aspectos da vida do produto, desde sua concepção, passando pela produção e manutenção até sua retirada do mercado.

De acordo com Matsokis e Kiritsis (2010), o principal objetivo de PLM é a gestão de todos os processos de negócio e dos dados gerados por eventos e ações dos vários agentes do ciclo de vida distribuídos ao longo das fases do ciclo de vida dos produtos.

Para Zancul (2009), PLM é uma abordagem para a gestão integrada dos processos de negócio e das informações relacionadas aos produtos.

Considerando as definições apresentadas anteriormente, pode-se notar que todas enfatizam a gestão integrada das informações e dos processos de negócios relacionados aos produtos ao longo do ciclo de vida. Ainda, para o CIMdata (2010), PLM não é somente tecnologia, mas deve ser considerado como uma abordagem de negócio para solucionar o problema da gestão das informações de produto, no qual os processos são tão importantes quantos os dados gerados ao longo do ciclo de vida.

Portanto PLM é definido como uma abordagem para a gestão integrada das informações e dos processos de negócios relacionados aos produtos ao longo do ciclo de vida e requer a utilização de sistemas de informação para apoiar sua implementação.

Revista Produção Online. Florianópolis, SC, v.12, n. 1, p. 159-184, jan./mar. 2012. 
A sigla PLM é, algumas vezes, conceituada como um termo que designa um tipo de software. Apesar das semelhanças nas definições sobre PLM ainda há certa confusão na distinção entre abordagem e sistema PLM, pois muitas vezes a implantação da abordagem PLM está vinculada à adoção de algum tipo de software. Porém, de uma maneira mais abrangente e comumente aceita é a definição de PLM como estratégia, também conhecida como conceito de negócio ou abordagem integrada (FELDHUSEN; BUNGERT, 2007).

Segundo Zancul (2009), os processos de negócio que compõem a abordagem PLM são: planejamento estratégico de produtos e planejamento do projeto; desenvolvimento de produtos; acompanhamento e retirada de produtos; gestão da configuração; e melhoria dos processos. Esse autor não comenta o processo de desenvolvimento de tecnologia, no entanto, é um importante processo de PLM que tem como objetivo transformar ideias em tecnologia e posteriormente, por meio do processo de desenvolvimento de produtos, empregá-las nos produtos.

Neste trabalho não será empregado o termo planejamento estratégico de produtos, mas planejamento estratégico da inovação (PEI), pois é mais amplo e não está restrito apenas aos produtos, mas, também, às tecnologias que poderão vir a ser utilizadas nesses produtos.

A gestão da configuração e melhoria dos processos, diferentemente de como foi proposto por Zancul (2009), não serão considerados processos de negócios da abordagem PLM, pois são processos de apoio e não estão diretamente relacionados aos produtos, mas aos processos de negócio da abordagem PLM.

Portanto, foram definidos cinco processos de negócio para a abordagem PLM que estão representados Figura 1.

Figura 1 - Processos de negócio da abordagem PLM

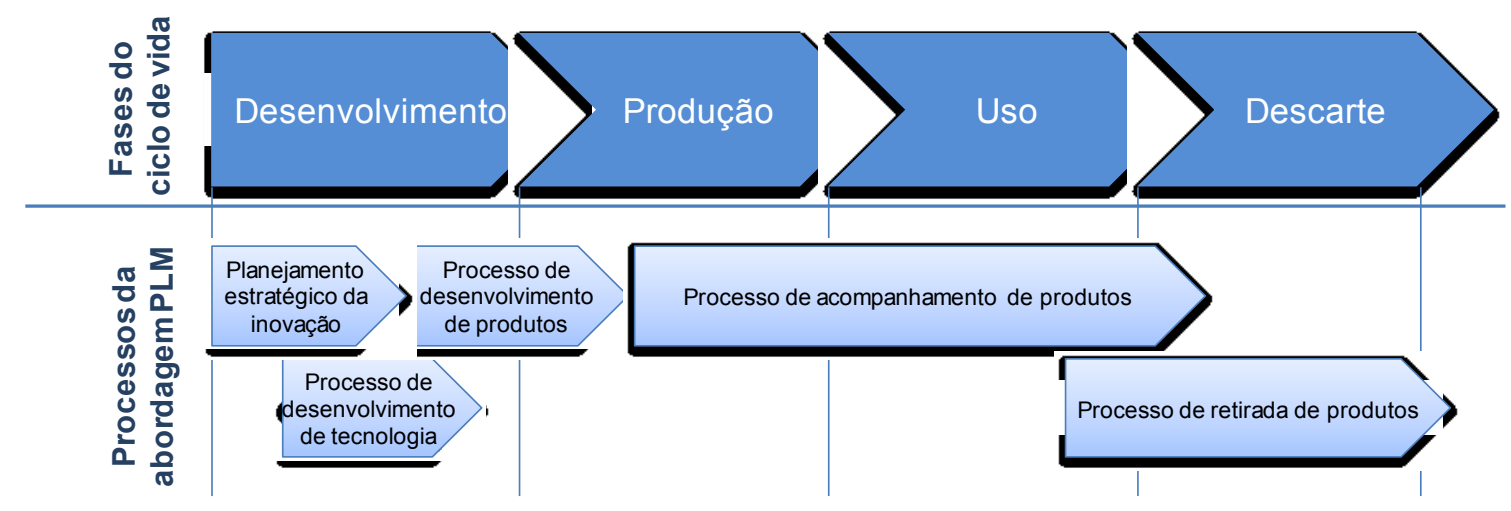

Revista Produção Online. Florianópolis, SC, v.12, n. 1, p. 159-184, jan./mar. 2012. 


\section{MEDIÇÃO DE DESEMPENHO}

É importante uma discussão a respeito das definições sobre a área de medição de desempenho, pois, de acordo com Neely (1998), a linguagem utilizada nesta área é muito confusa. Muitos autores utilizam diferentes palavras para descrever os mesmos conceitos.

Neely, Gregory e Platts (2005) propõem algumas definições que facilitarão o entendimento do tema em discussão:

- Medição de desempenho: pode ser definido como o processo de quantificar a eficiência e eficácia de uma ação;

- Medida de desempenho ou indicador de desempenho: pode ser definida como uma métrica usada para quantificar a eficiência e/ou a eficácia de uma ação; e

- Sistema de medição de desempenho (SMD): pode ser definido como um conjunto de métricas usadas para quantificar tanto a eficiência como a eficácia das ações.

Não há um consenso geral sobre a definição de sistemas de medição de desempenho, pois diferentes áreas de pesquisa possuem diferentes visões sobre as definições. Por exemplo, sob a óptica da gestão de operações, um SMD é percebido como um conjunto de métricas. Do ponto de vista da contabilidade gerencial, o SMD é sinônimo de planejamento de gestão e orçamento e, da perspectiva de controle estratégico, é tido com um conjunto de procedimentos para desdobramento da estratégia (FRANCO-SANTOS et al., 2007).

Apesar dos diferentes pontos de vista, os SMDs possuem características em comum e, ao longo das últimas décadas, evoluíram de uma medição baseada na eficiência e produtividade relacionadas ao custo para uma gestão de nível estratégico mais amplo que considera as operações a partir dos objetivos estratégicos (RADNOR; BARNES, 2007).

Quando o ambiente externo passou a interferir mais nas organizações, a medição de desempenho tradicional mostrou-se inadequada, principalmente devido a sua visão financeira de curto prazo e o foco excessivo na manufatura. Dessa forma, tornou-se necessário o pensamento de melhorias para a satisfação dos clientes e não apenas o controle das operações e a redução de custos. 
Por conta deste novo panorama, as empresas se viram forçadas a medir o desempenho que captasse o dinamismo desta nova realidade, dessa forma, além das medidas tradicionais é necessária a utilização de medidas de desempenho não tradicionais.

As principais caracteristicas desses novos SMD foram estudadas por Martins (1998) e são apresentadas a seguir por ordem de frequência de citação:

- Ser congruente com a estratégia competitiva;

- Ter medidas financeiras e não financeiras;

- Direcionar e apoiar a melhoria contínua;

- Identificar tendências e progressos;

- Facilitar o entendimento das relações de causa-e-efeito;

- Ser facilmente inteligível para os funcionários;

- Abranger todo o processo, desde o fornecedor até o cliente;

- Disponibilizar informações em tempo real para toda a organização;

- Ser dinâmico;

- Influenciar a atitude dos funcionários; e

- Avaliar o grupo e não o indivíduo.

Franco-Santos et al. (2007) conduziram uma extensa revisão bibliográfica, na qual foram pesquisadas as principais definições sobre sistemas de medição de desempenho. Para cada definição encontrada na pesquisa, havia uma perspectiva diferente que combinava diferentes tipos de características. No entanto, foi possível concluir que a base de cada definição era uma combinação das seguintes características: elementos dos SMD; papéis que os SMD executam; e processos que fazem parte dos SMD.

Os elementos são as propriedades ou características que compõe o SMD, os papéis são as finalidades ou funções que são executadas pelo SMD, e os processos são as ações que se combinam para constituir um SMD.

Um conjunto de medidas de desempenho que fornece um quadro passado e um desempenho futuro é muito útil para o sucesso da organização, mas isso não é suficiente. Geralmente, os dados de desempenho são apenas informações e se a informação não é entendida ou corretamente seguida, não ajudará a organização a 
melhorar. Ser capaz de analisar corretamente os dados e usá-los para boas tomadas de decisões são a essência da gestão de desempenho (MARTINS, 2002).

\section{MEDIÇÃO DE DESEMPENHO PARA A GESTÃo DO CICLO DE VIDA DE PRODUTOS}

Há poucas publicações que abordam especificamente a medição de desempenho para a gestão do ciclo de vida de produtos na literatura estudada. No entanto, há uma grande diversidade de trabalhos que abordam a medição de desempenho para o processo de desenvolvimento de produtos e pesquisa e desenvolvimento, que são temas contemplados pela abordagem PLM.

A maior parte dos processos de negócio que compõe a abordagem PLM tem uma natureza não repetitiva, ou seja, eles servem de referência para o desenvolvimento de projetos específicos. Assim, cada projeto, seja ele para desenvolvimento de tecnologia, melhoria ou desenvolvimento de um novo produto, é diferente do outro. Além disso, esses processos estão inseridos num ambiente de alta complexidade e incerteza, no qual vários projetos competem por recursos comuns e limitados, tornando, dessa forma, o controle e gestão desses processos uma tarefa difícil.

Não existem ações que possam ser tomadas para reduzir ou eliminar a maioria das dificuldades da medição de desempenho para PLM, pois essas dificuldades estão relacionadas à natureza dos processos. No entanto, existe na literatura pesquisada uma série de recomendações e princípios que auxilia o desenvolvimento de SMDs mais eficientes para PLM.

Hameri e Nihtila (1998) apresentam um conjunto de características dos SMDs para o PDP que, segundo esses autores, são essenciais para o desenvolvimento de um bom SMD. As características são apresentadas na Tabela 1. 
Tabela 1 - Características dos SMDs para o PDP

\begin{tabular}{ll}
\hline \multicolumn{1}{c}{ Características } & \multicolumn{1}{c}{ Descrição } \\
\hline Preventivo & $\begin{array}{l}\text { As medidas devem ser pró-ativas por natureza e, dessa forma, } \\
\text { possibilitar a identificação de problemas no início do ciclo de vida do } \\
\text { projeto. } \\
\text { O sistema de medição deve ser composto por um número restrito de } \\
\text { medidas simples e fáceis de entender. }\end{array}$ \\
Multifuncional & $\begin{array}{l}\text { As medidas devem descrever os resultados do PDP. } \\
\text { Direcionado ao time }\end{array}$ \\
Franco & $\begin{array}{l}\text { As medidas devem ser definidas pelo time de projeto com base nas } \\
\text { O conjunto de medidas deve ser comunicado de uma forma aberta em } \\
\text { toda a organização }\end{array}$ \\
Visual & $\begin{array}{l}\text { As métricas devem ser comunicadas através de representações } \\
\text { visuais dos dados. }\end{array}$ \\
\hline
\end{tabular}

Fonte: Adaptado de Hameri e Nihtila (1998, p. 169)

As características apresentadas são de fato úteis e podem auxiliar na concepção de um SMD, porém os autores não abordam características importantes para os SMDs, como por exemplo, o equilíbrio entre medidas quantitativas e qualitativas, financeiras e não financeiras. Além disso, em nenhum momento os autores relatam a importância de se definir medidas que apoiem a melhoria continua ou indicadores que possam ser utilizados para influenciar o comportamento das pessoas.

Segundo Tatikonda (2008), há muita confusão, tanto na prática como na academia, na definição das características dos indicadores de desempenho para o PDP. O autor propõe quatro características.

A primeira é o objetivo do indicador de desempenho, que tem como finalidade estimular a discussão sobre a importância do indicador sob o ponto de vista gerencial.

A segunda característica é o objeto de interesse do indicador de desempenho, também conhecido como unidade de observação ou unidade de análise. Os indicadores devem ser concebidos para medir o objeto que se destina medir. Do contrário, pode haver informações irrelevantes. Além disso, outro problema que pode acontecer quando se negligencia a unidade de observação são comparações errôneas, pois, corre-se o risco de comparar indicadores de diferentes níveis de agregação. 
A terceira característica é o tipo de medida, que pode ser: qualitativa ou quantitativa; de resultado ou de tendência; financeira ou não financeiras; e tática (orientada ao curto prazo) ou estratégica (orientada ao longo prazo).

Por fim, a última característica citada pelo autor é o alinhamento entre as métricas, ou seja, na maior parte das medidas de desempenho é possível estabelecer uma relação de causa e efeito e, esta relação, auxilia o processo de tomada de decisão, pois se pode chegar com maior facilidade aos problemas raízes.

De acordo com Chiesa et al. (2009a), os SMDs para P\&D são constituídos de cinco elementos principais: i) objetivos; ii) dimensões da medição de desempenho; iii) indicadores de desempenho; iv) estrutura da medição; e v) processo de medição.

A definição dos objetivos é uma escolha importante para a concepção de um SMD para $P \& D$, pois eles influenciam a escolha dos outros elementos constituintes do SMD (CHIESA; FRATTINI, 2007). Além disso, para o sucesso da medição de desempenho é necessário que as dimensões a serem monitoradas sejam selecionadas adequadamente. As perspectivas propostas pelo Balanced Scorecard (BSC) - financeira, clientes, processos internos e aprendizado e crescimento também parecem adequadas para agrupar os indicadores relacionados aos processos de PLM (KERSSENS-VAN DRONGELEN; BILDERBEEK, 1999; GODENER; SODERQUIST, 2004; CHIESA et al., 2009b).

A definição da estrutura permite identificar a unidade de análise, cujo desempenho passa a ser monitorado e, dessa maneira, pode-se fazer comparações entre indicadores de mesmo nível.

A distinção entre indicadores quantitativos e qualitativos é relevante, visto que um equilíbrio entre esses dois tipos de medida permite capturar aspectos intangíveis e, ao mesmo tempo, reduzir a subjetividade da avaliação (CHIESA et al. 2009a).

Dois pontos são importantes para o processo de medição. O primeiro é a definição de padrões que devem ser seguidos para avaliar a realização dos objetivos pretendidos pela empresa. Eles podem ser definidos internamente como objetivos futuros estabelecidos com base na estratégia da empresa ou nas informações de desempenhos passados, ou externamente que são definidos por meio de benchmarking. O segundo ponto é a frequência de medição que pode ser regular (semanal, mensal etc.) ou por marcos, ou seja, os resultados dos indicadores são analisados em apenas alguns momentos específicos do projeto.

Revista Produção Online. Florianópolis, SC, v.12, n. 1, p. 159-184, jan./mar. 2012. 
Existem fatores internos e externos à organização que podem influenciar na definição dos elementos de um SMD para PLM e, consequentemente, influenciam na escolha dos indicadores de desempenho (CHIESA et al., 2008; KERSSENS-VAN DRONGELEN; BILDERBEEK, 1999; CHIESA et al. 2009b).

Apesar das dificuldades inerentes à medição de desempenho dos processos da abordagem PLM, o desenvolvimento de um SMD para PLM é possível, haja vista os casos apresentados na literatura pesquisada. Além disso, as recomendações, características e elementos propostos forneceram um portfólio de conhecimento que pode ser utilizado para superar tais dificuldades e facilitar o desenvolvimento de SMDs para PLM.

A seguir, na próxima seção, é apresentado o procedimento metodológico utilizado neste trabalho.

\section{METODOLOGIA}

Neste trabalho foi realizada uma revisão bibliográfica sistemática com o objetivo de identificar recomendações para o desenvolvimento de um SMD para PLM e os principais indicadores de desempenho relacionados à abordagem PLM. Dessa forma, utilizou-se uma adaptação do método proposto por Biolchini et al. (2007), o qual é composto por três fases conforme a

Figura 2.

Figura 2 - Processo de condução de revisão sistemática

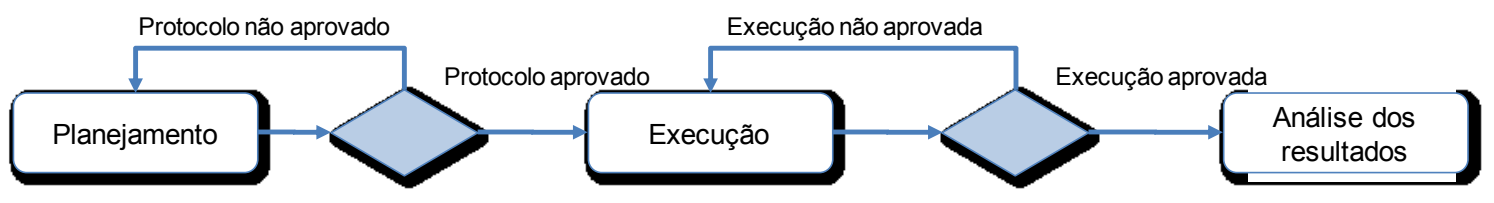

Fonte: Adaptado de Biolchini et al. (2007, p. 142)

Na fase de planejamento, os objetivos da revisão sistemática são listados e um protocolo de planejamento é definido. Esse protocolo especifica a questão central da pesquisa e os métodos que serão usados para executar a revisão sistemática. A etapa de execução envolve a identificação, seleção e avaliação dos estudos primários conforme os critérios de inclusão definidos no protocolo. Uma vez que os estudos primários são selecionados, os dados desses estudos são extraídos

Revista Produção Online. Florianópolis, SC, v.12, n. 1, p. 159-184, jan./mar. 2012. 
e sintetizados durante a fase de análise dos resultados. Este método não propõe que se faça uma pesquisa cruzada entre os trabalhos selecionados, ou seja, pode haver trabalhos que referenciam outros autores e que merecem atenção do pesquisador. Portanto, além dos trabalhos selecionados pelo método adotado, realiza-se a pesquisa cruzada e são identificados outros trabalhos citados nos estudos primários que o pesquisador julga importante e são incluídos para análise posterior.

\section{REVISÃO BIBLIOGRÁFICA SISTEMÁTICA}

A revisão bibliográfica sistemática é um meio de identificar, avaliar e interpretar todos os trabalhos de pesquisas relevantes para uma questão de pesquisa específica, ou um tópico de uma área, ou ainda um fenômeno de interesse (KITCHENHAM, 2007). Esse procedimento de pesquisa é estruturado, incluindo processos replicáveis, científicos e transparentes, para minimizar vieses (TRANFIELD, DEYER e SMART, 2003).

Esta seção foi dividida em três subseções que representam as fases do método proposto por Biolchini et al. (2007).

\subsection{Planejamento}

O objetivo da revisão bibliográfica sistemática foi identificar os principais indicadores de desempenho utilizados para a gestão do ciclo de vida de produtos bem como as principais recomendações para o desenvolvimento de um SMD para PLM. As questões de pesquisas formuladas para a revisão bibliográfica sistemática foram: quais são os principais indicadores de desempenho utilizados para a gestão do ciclo de vida de produtos?; Quais as principais recomendações apresentadas na literatura para o desenvolvimento de um SMD para PLM?

As bases de dados eletrônicas selecionadas como fonte de buscas para os estudos primários foram: ISI Web of Knowledge, Emerald, Science Direct, Scopus e Engineering Village. Os idiomas escolhidos foram o inglês, uma vez que é um idioma universalmente aceito para redação de trabalhos científicos e por ser encontrado na maioria das bases de dados pesquisadas, e o português, por ser a língua materna 
do pesquisador. Foi considerado qualquer tipo de trabalho científico que abordasse a medição de desempenho para algum processo de negócio da abordagem PLM.

As palavras-chave consideradas nas buscam foram "performance measurement" e "product lifecycle management". Pela combinação dos sinônimos das palavras-chave foi formada a seguinte string de busca: ("performance measurement" OR "performance indicator" OR "performance indicators" OR "performance measure") AND ("product lifecycle management" OR "product development" OR "research and development").

O processo de seleção dos estudos primários foi dividido em dois passos: seleção preliminar; e seleção final. Na seleção preliminar, a string de busca foi submetida às bases de dados eletrônicas e feita a leitura do resumo e do capítulo introdutório dos trabalhos recuperados. Caso o trabalho apresentasse ao menos um critério de inclusão, ele era selecionado para o processo de seleção final. $\mathrm{Na}$ seleção final foi realizada a leitura completa dos trabalhos selecionados, e os que atenderam aos mesmos critérios de inclusão, foram selecionados para a extração de informações. Os critérios de inclusão definidos foram:

- Critério de inclusão 1: Proposição e/ou estudos sobre indicadores de desempenho relacionados aos processos de negócio da abordagem PLM.

- Critério de inclusão 2: Informações sobre atributos de indicadores de desempenho relacionados aos processos de negócio da abordagem PLM.

- Critério de inclusão 3: Recomendações para o desenvolvimento de um SMD para PLM.

Foi também realizada uma pesquisa cruzada que consiste na identificação de outras publicações pela análise das referências citadas nos trabalhos primários. As publicações identificadas pela pesquisa cruzada são então analisadas segundo os critérios de inclusão e, caso sejam selecionadas, suas informações são extraídas.

Como estratégia de extração dos resultados da revisão bibliográfica sistemática, para cada artigo selecionado foi registrada sua referência, ano de publicação, nome do periódico ou conferência, metodologia empregada, relação de indicadores de desempenho e as recomendações para o desenvolvimento de um SMD. 


\subsection{Execução}

A etapa de execução ocorreu entre os meses de Novembro de 2009 e Abril de 2010. Essa etapa compreendeu a identificação, seleção e avaliação dos estudos primários conforme os critérios de inclusão e exclusão definidos na fase de planejamento.

Nessa fase, a string de busca foi submetida às bases de dados eletrônicas resultando em 372 publicações, sendo 116 da ISI Web of Knowledge, 73 da Emerald, 20 da Science Direct, 104 da Scopus e 59 da Engineering Village. Para apoio à manipulação e tratamento dos trabalhos recuperados foi utilizado o gerenciador de referências Mendeley Desktop.

A seleção das publicações seguiu o método definido na fase de planejamento. Da seleção preliminar, chegou-se a 123 publicações. Na seleção final, os 123 trabalhos foram lidos por completo e mais 30 artigos foram selecionados por meio da pesquisa cruzada, chegando-se a 48 publicações para terem suas informações extraídas. A

Figura 3 apresenta a quantidade de publicações selecionadas ao longo da fase de execução.

Figura 3 - Número de publicações encontradas e selecionadas

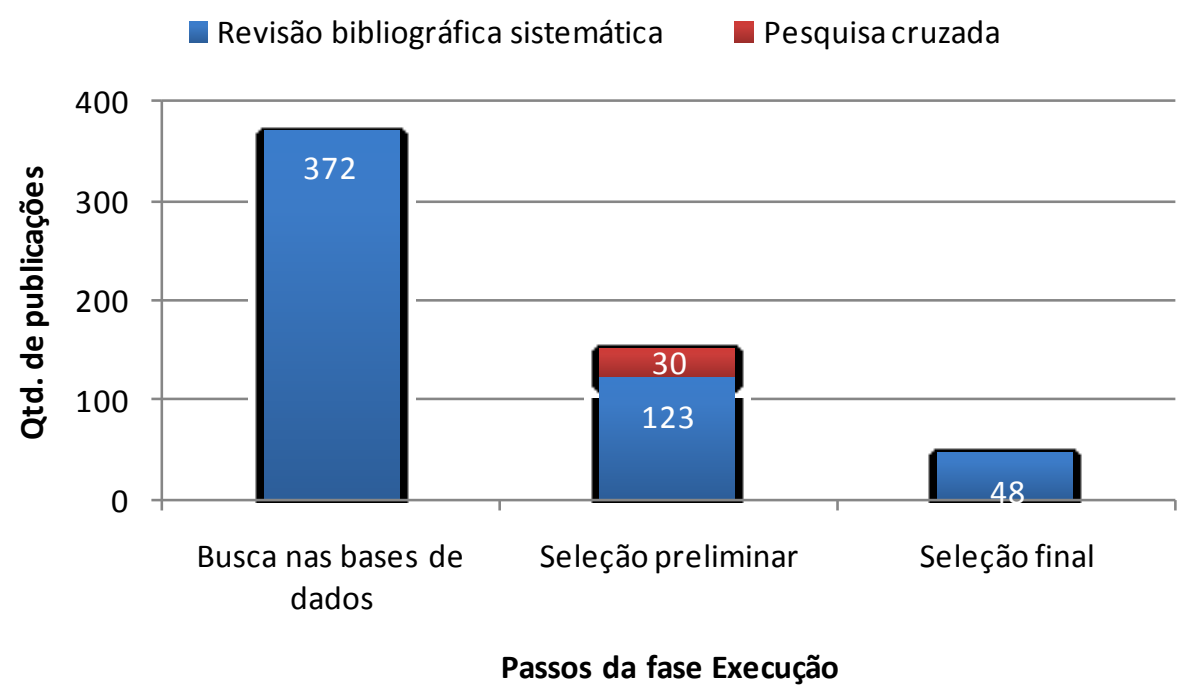

Para cada publicação selecionada, as seguintes informações foram registradas: referência; ano da publicação; nome do periódico ou conferência; 
metodologia empregada; proposição de perspectivas; proposição de recomendações; e proposição de indicadores de desempenho.

\subsection{Análise}

Esta seção foi dividida em três subseções. Na primeira, são discutidas as informações referentes à distribuição das publicações selecionadas e, dessa forma, são apresentados os principais periódicos e autores consultados, assim como as metodologias empregadas nos trabalhos consultados, bem como a distribuição de trabalhos ao longo dos anos. Na segunda subseção, são apresentadas as principais recomendações citadas nos estudos. Por fim, na última subseção, são apresentados os principais indicadores de desempenho para PLM identificados na literatura estudada.

\subsubsection{Distribuição das publicações}

Esta análise tem como objetivo apresentar os principais autores, periódicos e metodologias empregadas nos trabalhos que abordam os temas desta pesquisa bem como sua evolução ao longo do tempo.

Foram identificados 90 autores nas 48 publicações provenientes da seleção final. Desse total, apenas 15 aparecem com mais de uma publicação e apenas sete desses autores foram os primeiros autores das publicações, conforme ilustra a Figura 4. 
Figura 4 - Principais autores que tratam os temas abordados nesta pesquisa

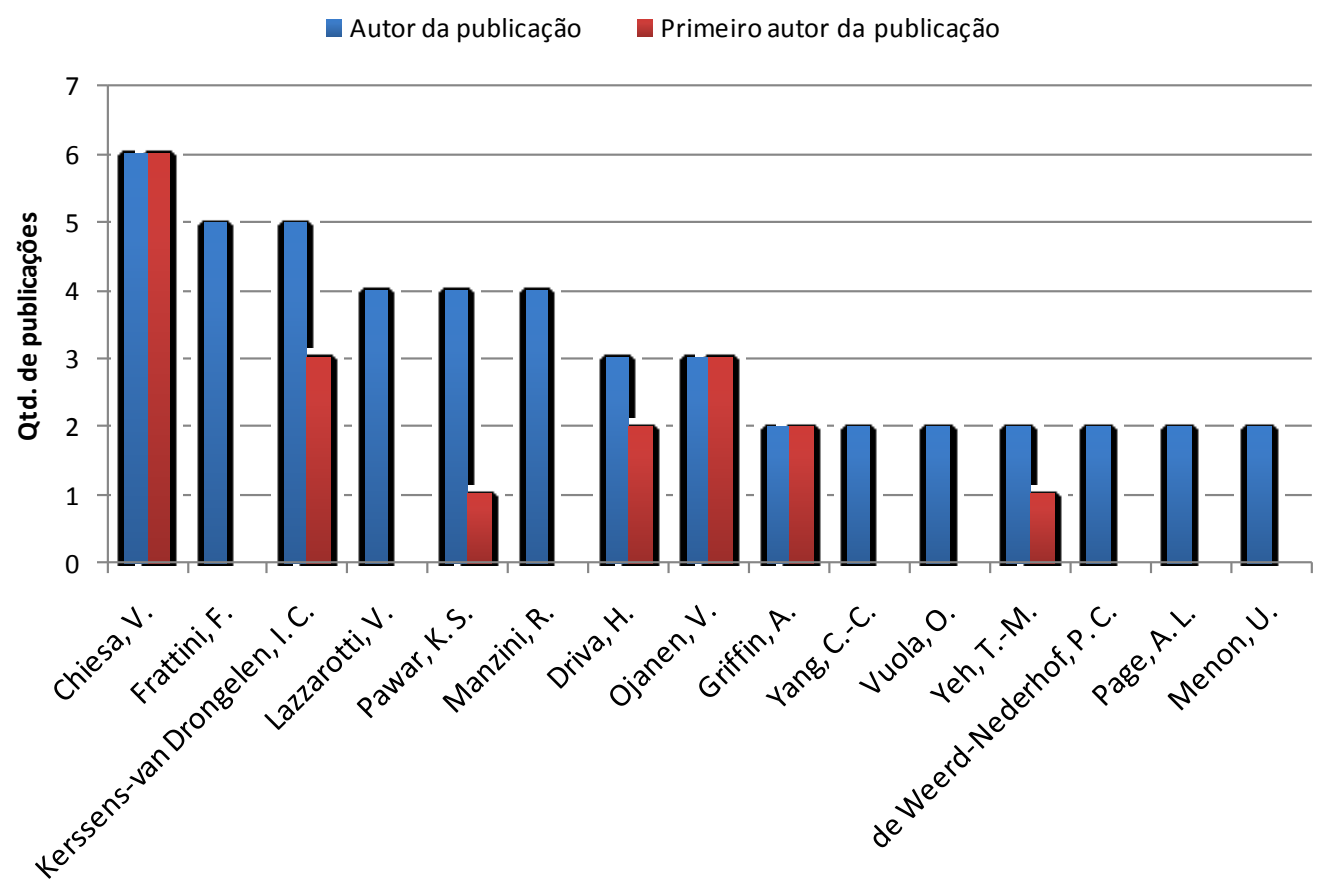

Autores

Do total de autores, apenas cinco possuem mais de duas publicações como primeiros autores. Dessa forma, considerando que os principais autores relacionados ao tema possuem pelo menos duas publicações como primeiros autores, pode-se considerar, em ordem decrescente de importância, que os principais autores que tratam sobre o tema são: i) Chiesa, V.; ii) Kerssens-van Drongelen, I. C.; iii) Ojanen, V.; iv) Driva, H.; e iv) Griffin, A.

Dos 48 trabalhos escolhidos na seleção final, dois são livros, um é tese de doutorado, outro artigo de congresso e outro working paper, há, portanto, 43 artigos de periódicos internacionais. Desse total, apenas seis possuíam mais de dois artigos selecionados. Dessa forma, considerando que os principais periódicos relacionados aos temas de pesquisa possuem pelo menos dois artigos selecionados, conclui-se que os principais periódicos, em ordem decrescente de importância, são: i) R\&D Management; ii) Journal of Product Innovation Management; iii) International Journal of Production Economics; iv) Research Technology Management; v) Creativity and Innovation Management; e vi) International Journal of Operations and Production Management.

A Figura 5 apresenta a quantidade de artigos selecionados em relação aos principais periódicos que tratam os temas abordados nesta pesquisa.

Revista Produção Online. Florianópolis, SC, v.12, n. 1, p. 159-184, jan./mar. 2012. 
Figura 5 - Principais periódicos que tratam os temas abordados nesta pesquisa

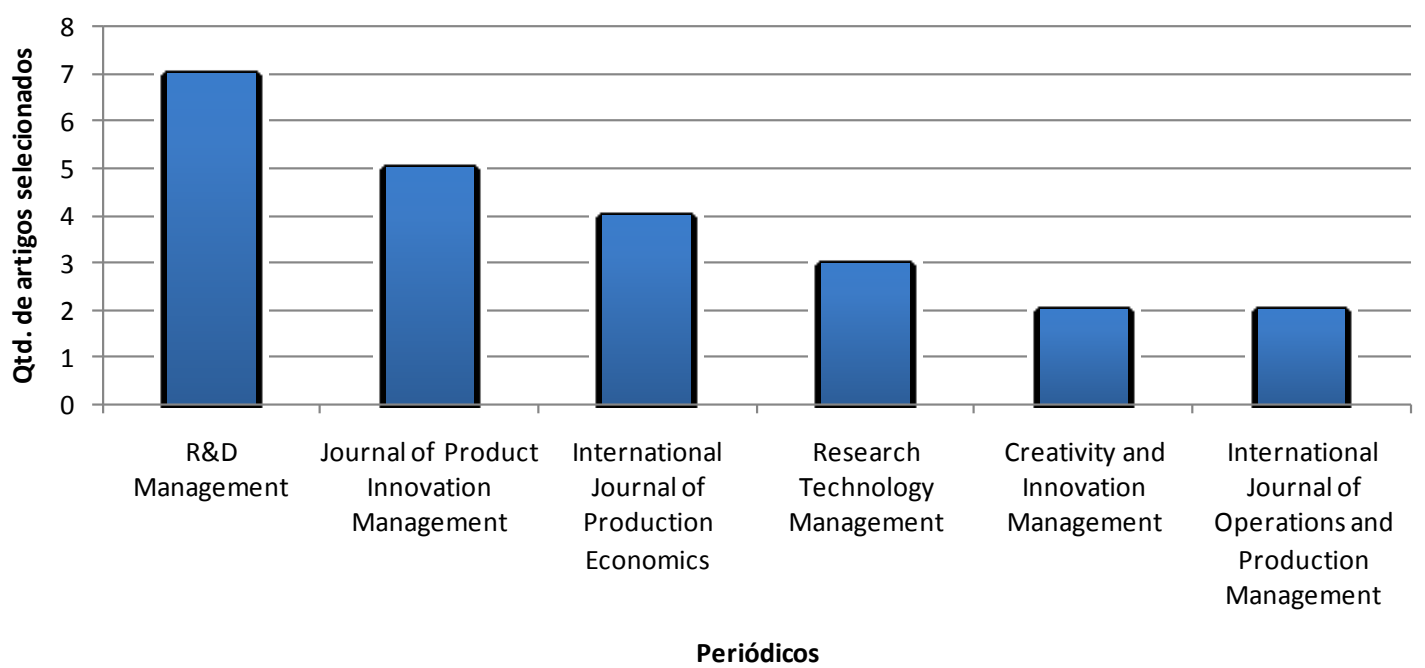

Foram utilizados três tipos de metodologia nos trabalhos selecionados: estudo de caso, survey e revisão bibliográfica. Na Figura 6, pode-se observar a predominância do estudo de caso nos trabalhos (46\%), seguido pela survey $(21 \%)$ e revisão bibliográfica (15\%). Ainda, seis trabalhos (12\%) utilizaram tanto estudo de caso quanto survey e em três trabalhos não foram relatadas a metodologia de pesquisa empregada.

Figura 6 - Metodologias empregadas publicações selecionadas

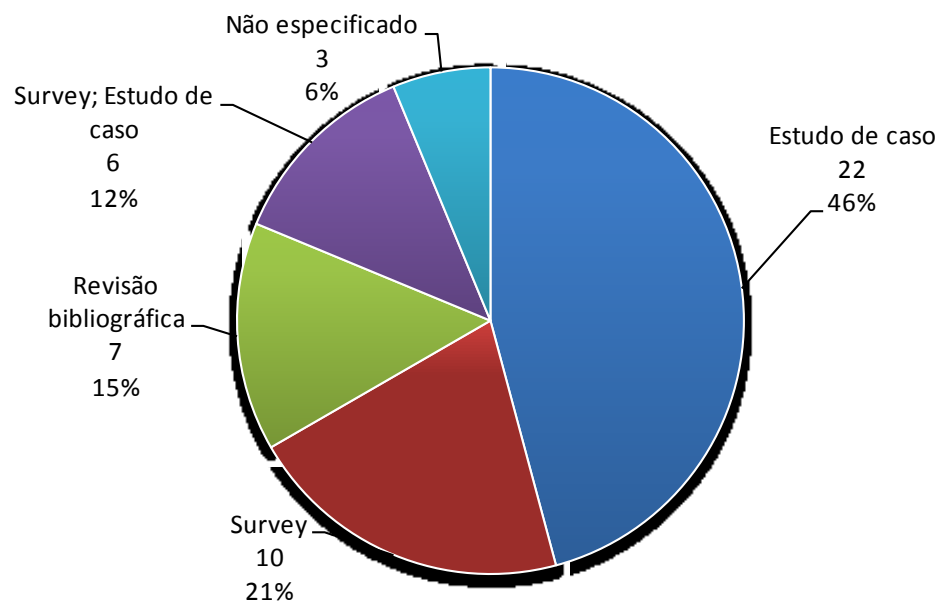

A Figura 7 apresenta a distribuição anual dos trabalhos selecionados. O gráfico dessa figura aponta para uma tendência crescente de publicações. Além disso, pode ser observado que $75 \%$ dos trabalhos selecionados foram publicados nos últimos dez anos.

Revista Produção Online. Florianópolis, SC, v.12, n. 1, p. 159-184, jan./mar. 2012. 
Figura 7 - Distribuição anual dos trabalhos selecionados

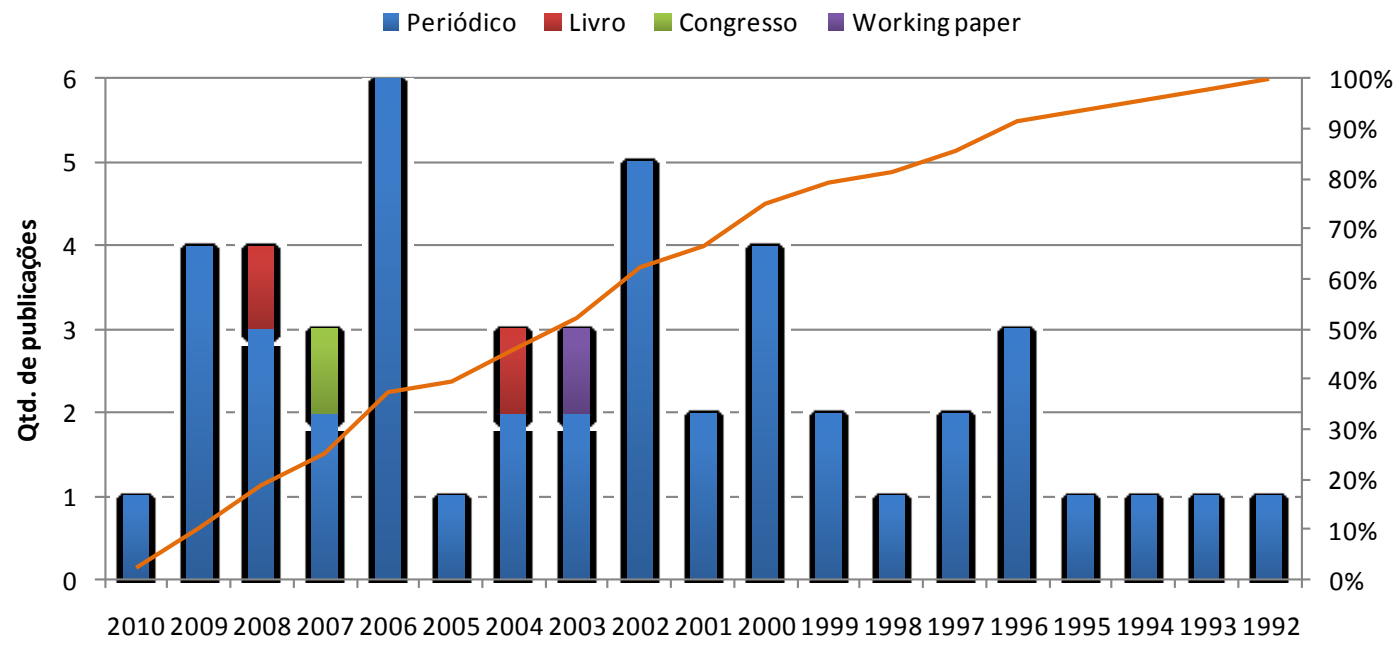

Ano

Como discutido na seção 4 , as publicações não tratam especificamente a medição de desempenho para a gestão do ciclo de vida de produtos, mas para o processo de desenvolvimento de produtos ou para a pesquisa e desenvolvimento, ambos englobados pela abordagem PLM. A Figura 8 apresenta a distribuição dos trabalhos selecionados em relação ao termo empregado.

Figura 8 - Termos empregados nas publicações selecionadas

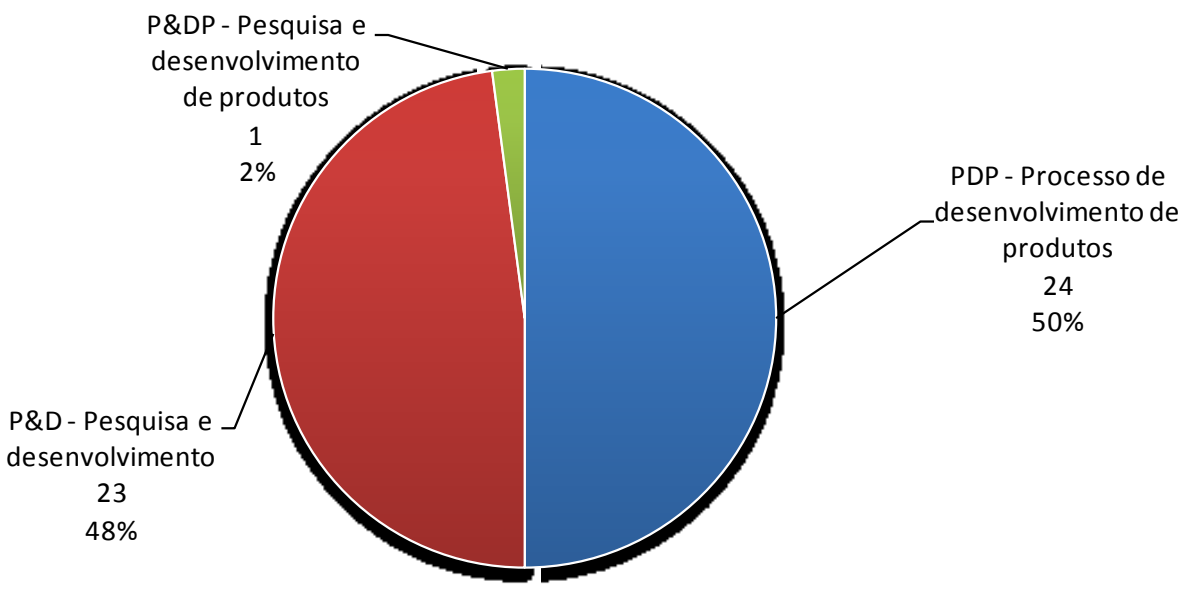

Como observado na figura anterior, nenhum trabalho selecionado emprega o termo gestão do ciclo de vida de produtos, mas termos que são englobados por este conceito.

Revista Produção Online. Florianópolis, SC, v.12, n. 1, p. 159-184, jan./mar. 2012. 


\subsubsection{Recomendações para o desenvolvimento de um smd para plm}

Foram identificados oito trabalhos que apresentam recomendações para o desenvolvimento de um SMD para PLM. A relação de trabalhos e a quantidade de recomendações são apresentadas na Figura 9.

Figura 9 - Trabalhos que relataram recomendações para o desenvolvimento de um SMD para PLM

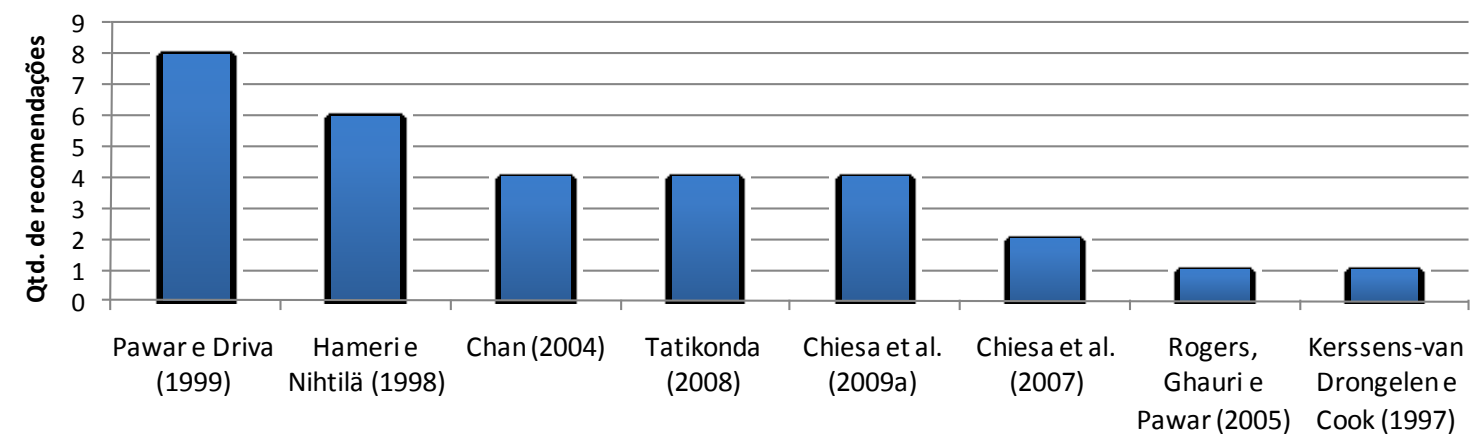

Na tabela 2 são apresentadas as principais recomendações encontradas na literatura para o desenvolvimento de SMDs para PLM.

Tabela 2 - Recomendações para desenvolvimento de um SMD para PLM

(continua)

\begin{tabular}{l} 
Recomendação \\
\hline As medidas de desempenho devem descrever os resultados dos \\
processos de desenvolvimento. \\
Apesar das medidas de desempenho que registram aspectos negativos \\
como problemas de confiabilidade, gargalos e custo serem importantes, \\
um sistema balanceado também deve incorporar medidas de sucesso. \\
As medidas de desempenho devem estar alinhadas com os objetivos \\
estratégicos da empresa. \\
As medidas de desempenho devem ser comunicadas através de \\
representações visuais dos dados. \\
As medidas de desempenho devem ser definidas pelo time de projeto com \\
base nas orientações estratégicas da alta gerência. \\
As medidas de desempenho devem ser pró-ativas por natureza e, dessa \\
forma, possibilitar a identificação de problemas no início do ciclo de vida \\
do projeto. \\
Crie um balanceamento entre as medidas, ou seja, faça uma combinação \\
de medidas quantitativas e qualitativas, de resultado e de tendência, \\
financeira e não financeira, tática (orientada ao curto prazo) e estratégia \\
(orientada ao longo prazo). \\
Defina as unidades de análise na qual o indicador se propõe a medir: \\
indivíduo, departamento, unidade de negócio, empresa etc. \\
Defina mecanismos para avaliação periódica dos resultados dos \\
indicadores de desempenho.
\end{tabular}

Hameri e Nihtilä (1998)

Pawar e Driva (1999)

Chan (2004)

Chiesa et al. (2007)

Hameri e Nihtilä (1998)

Hameri e Nihtilä (1998)

Hameri e Nihtilä (1998)

Chan (2004)

Chiesa et al. (2009a)

Pawar e Driva (1999)

Tatikonda (2008)

Chiesa et al. (2009a)

Tatikonda (2008)

Chan (2004)

Revista Produção Online. Florianópolis, SC, v.12, n. 1, p. 159-184, jan./mar. 2012. 


\begin{tabular}{|c|c|}
\hline Recomendação & Fonte \\
\hline $\begin{array}{l}\text { Estabeleça uma relação de causa e efeito, pois esta relação auxilia o } \\
\text { processo de tomada de decisão e chega-se mais facilmente aos } \\
\text { problemas raízes. }\end{array}$ & Tatikonda (2008) \\
\hline $\begin{array}{l}\text { Garanta que o sistema de medição monitore o desempenho em estágios } \\
\text { específicos do desenvolvimento, bem como avalie o desempenho global } \\
\text { do projeto. Assim, uma combinação de medidas de produtos (custo de } \\
\text { componentes, defeitos de concepção) e medidas de processo (time to } \\
\text { market) será útil. }\end{array}$ & Pawar e Driva (1999) \\
\hline $\begin{array}{l}\text { Garanta uma elevada transparência nas medidas de desempenho de } \\
\text { nível de projeto. }\end{array}$ & $\begin{array}{l}\text { Rogers, Ghauri e Pawar } \\
\text { (2005) }\end{array}$ \\
\hline $\begin{array}{l}\text { Identifique os objetivos da medição de desempenho. Exemplo: motivar } \\
\text { pessoal; monitorar atividades em progresso; avaliar a lucratividade dos } \\
\text { projetos; selecionar áreas e projetos de investimento; melhorar a eficácia } \\
\text { dos processos de PLM; melhorar a comunicação e coordenação; reduzir } \\
\text { incertezas; estimular aprendizado. }\end{array}$ & $\begin{array}{l}\text { Chiesa et al. (2007) } \\
\text { Chiesa et al. (2009a) } \\
\text { Tatikonda (2008) }\end{array}$ \\
\hline $\begin{array}{l}\text { Inclua pessoas envolvidas nos processos de desenvolvimento na } \\
\text { concepção do SMD. }\end{array}$ & $\begin{array}{l}\text { Kerssens-van Drongelen } \\
\text { e Cook (1997) }\end{array}$ \\
\hline $\begin{array}{l}\text { Inicie o desenvolvimento do SMD com medidas de desempenho simples } \\
\text { e exequíveis que irão fornecer resultados tangíveis e avance para as } \\
\text { medidas mais complexas posteriormente. }\end{array}$ & $\begin{array}{l}\text { Chan (2004) } \\
\text { Pawar e Driva (1999) }\end{array}$ \\
\hline $\begin{array}{l}\text { Medidas de desempenho em nível individual são inapropriadas em um } \\
\text { ambiente em equipe. O desempenho da equipe é o que importa. }\end{array}$ & Pawar e Driva (1999) \\
\hline $\begin{array}{l}\text { Não deixe que as equipes de projeto se desmotivem por estarem } \\
\text { inseguros em medir precisamente uma nova variável, pois ao longo do } \\
\text { tempo, ela pode ser aperfeiçoada. }\end{array}$ & Pawar e Driva (1999) \\
\hline $\begin{array}{l}\text { O conjunto de medidas de desempenho deve ser comunicado de uma } \\
\text { forma aberta em toda a organização. }\end{array}$ & Hameri e Nihtilä (1998) \\
\hline $\begin{array}{l}\text { O sistema de medição de desempenho deve ser composto por um } \\
\text { número restrito de medidas simples e fáceis de entender. }\end{array}$ & Hameri e Nihtilä (1998) \\
\hline Os dados devem ser fáceis de coletar, registrar e acessar. & Pawar e Driva (1999) \\
\hline $\begin{array}{l}\text { Se a medição de desempenho ainda é incipiente para a empresa, não se } \\
\text { deve propor muitas medidas. }\end{array}$ & Pawar e Driva (1999) \\
\hline $\begin{array}{l}\text { Selecione adequadamente as dimensões de desempenho a serem } \\
\text { monitoras. Exemplo: desempenho financeiro, clientes, eficiência dos } \\
\text { processos de PLM e aptidão para inovação. }\end{array}$ & Chiesa et al. (2009a) \\
\hline
\end{tabular}

\subsubsection{Lista de indicadores de desempenho para PLM}

Nesta seção são apresentados os principais indicadores de desempenho e suas respectivas informações identificadas na literatura estudada.

Foram identificados 914 indicadores de desempenho de 44 fontes distintas. Entretanto, 41 fontes são provenientes do processo de revisão bibliográfica sistemática. As outras três foram identificadas previamente à revisão sistemática. 
Vinte e um trabalhos citaram algum tipo de dimensão e as mais citadas foram: clientes; financeira; processos internos; e aprendizagem e crescimento, conforme ilustrado na Figura 10.

Figura 10 - Dimensões de desempenho para a gestão do ciclo de vida de produtos

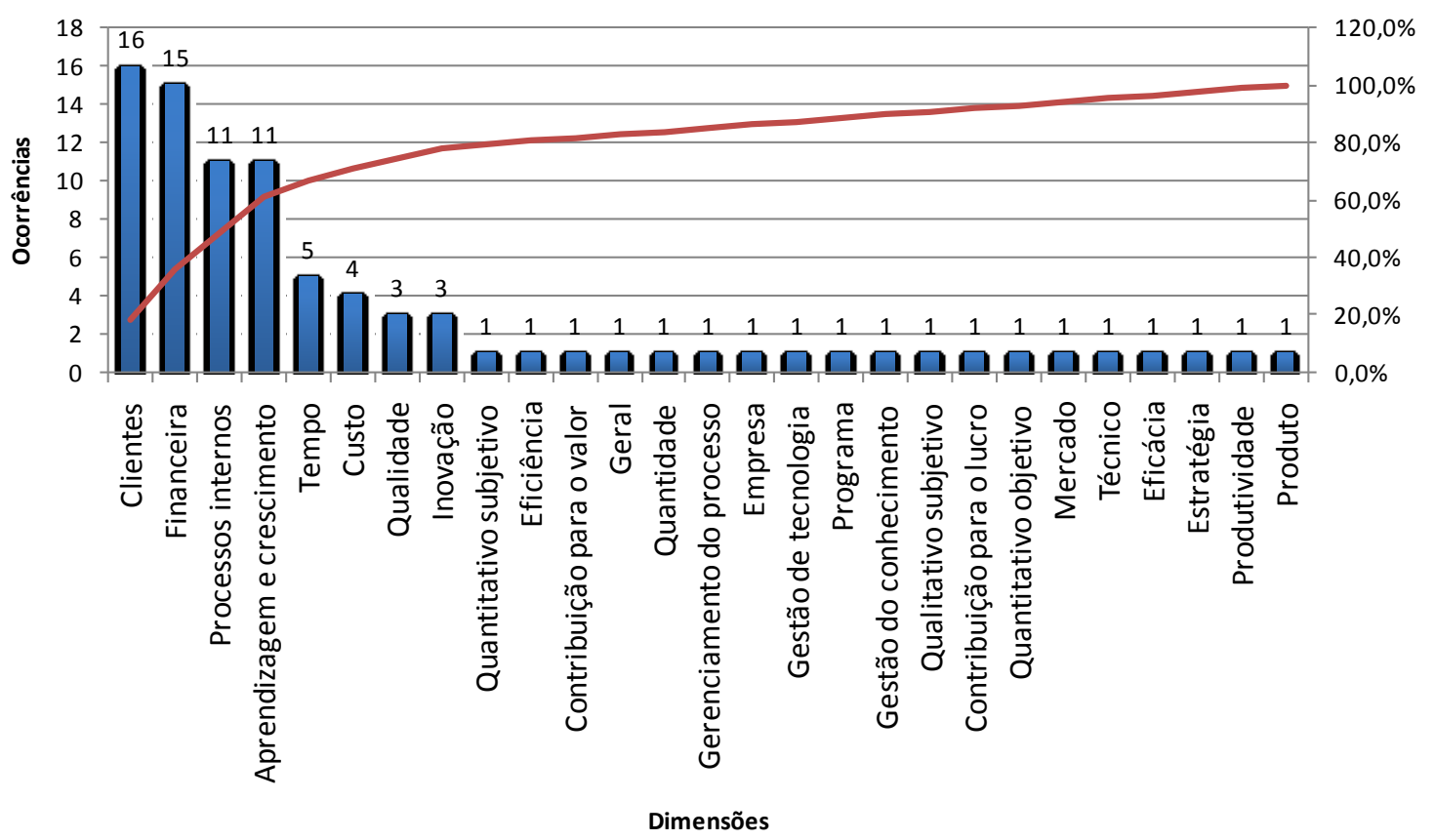

Como observado no gráfico da figura anterior, as 4 dimensões mais citadas são as mesmas propostas pelo Balanced Scorecard (BSC) e correspondem a $61 \%$ do total de ocorrências.

Quinze trabalhos citaram algum tipo de unidade de análise para os indicadores de desempenho e as mais citadas foram: projeto; indivíduo; empresa; departamento; e time. Juntas, essas unidades de análise representam $74 \%$ do total de ocorrência, conforme ilustra a Figura 11. 
Figura 11 - Unidades de análise para a gestão do ciclo de vida de produtos

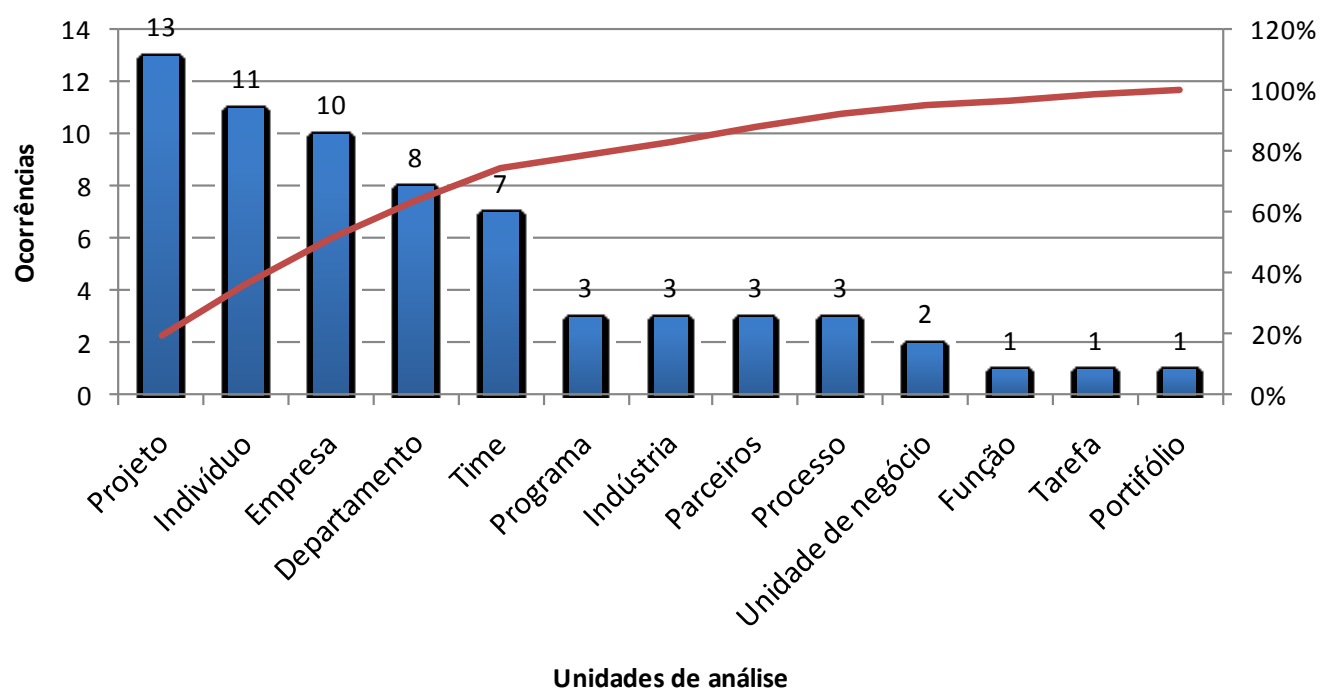

Como pode ser observado na figura anterior, dos 15 trabalhos que citam alguma unidade de análise, 13 citam projeto. As outras unidades de análise estão relacionadas com as medidas de desempenho dos processos de desenvolvimento, no entanto, para diferentes níveis ou unidades de análise, por exemplo: indivíduo, time, departamento, empresa e indústria.

Dos 914 indicadores de desempenho identificados, apenas 11, ou seja, 1,2\% do total apresentaram sua fórmula de cálculo.

Inicialmente, os indicadores de desempenho identificados na literatura estudada foram incluídos em uma planilha na qual foram registradas as seguintes informações: título original; título adaptado; fórmula especificada na publicação; processo PLM; perspectiva do BSC; tipo de indicador; e fonte. O objetivo da coluna "Título adaptado", foi padronizar o nome dos indicadores identificados que possuíam nomes distintos, porém com o mesmo significado.

Posteriormente, as informações da coluna "Título adaptado" foram revisadas para se chegar a uma padronização dos títulos dos indicadores de desempenho.

Dessa forma, chegou-se à lista final de indicadores de desempenho que possui as seguintes informações: título do indicador; perspectiva do BSC; processo PLM; tipo de indicador; e ocorrência na literatura estudada.

A lista final possui 296 indicadores de desempenho, ou seja, houve uma redução de $68 \%$ no número de indicadores de desempenho em relação à lista inicial. Nessa nova lista, 18 indicadores de desempenho foram citados ao menos 10 vezes, conforme apresenta a figura 12.

Revista Produção Online. Florianópolis, SC, v.12, n. 1, p. 159-184, jan./mar. 2012. 
Figura 12 - Indicadores de desempenho com maiores ocorrências na literatura estudada

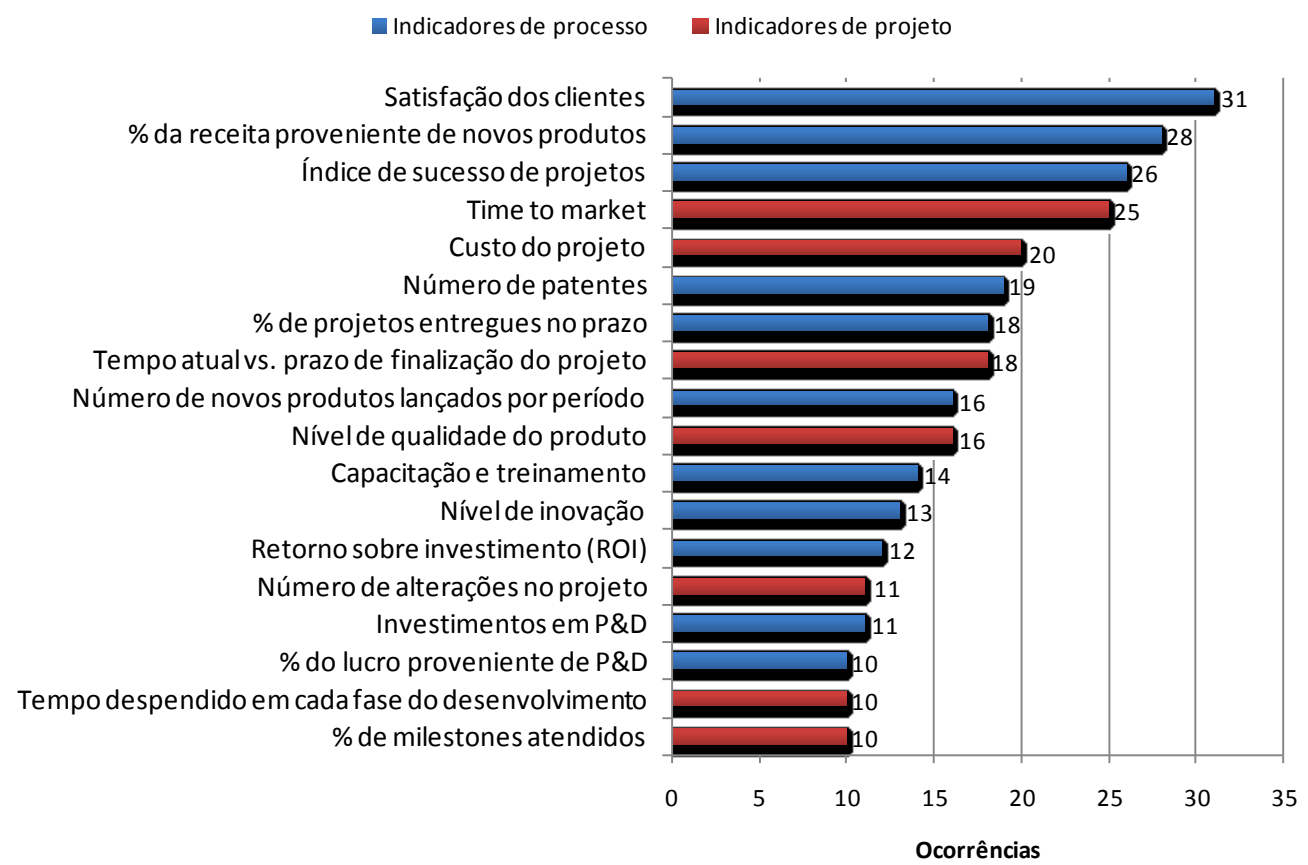

\section{CONSIDERAÇÕES FINAIS}

Como relatado, a medição de desempenho e o desenvolvimento de um SMD para a gestão do ciclo de vida de produtos é uma tarefa difícil e complexa. Este trabalho propôs um aprofundamento nesse tema visando identificar, por meio de uma revisão bibliográfica sistemática, uma coletânea de recomendações para tal desenvolvimento e a relação de indicadores de desempenho para PLM mais citados na literatura.

Dessa forma, espera-se que este trabalho possa contribuir com a literatura, visto que há poucos trabalhos que abordam a medição de desempenho para a gestão do ciclo de vida de produtos, pois a maior parte dos trabalhos encontrados aborda a medição de desempenho de uma maneira mais restrita, ou seja, trata apenas alguns dos processos de negócio da abordagem PLM. Além disso, não foram encontradas publicações semelhantes que realizaram uma revisão bibliográfica sistemática como a apresentada neste trabalho. Espera-se, também, que as empresas possam empregar os resultados deste trabalho para as orientarem na condução de um projeto de desenvolvimento de um SMD para PLM. 
As respectivas informações dos indicadores de desempenho apresentadas na lista de indicadores foram definidas pelos autores, portanto, pode haver discordâncias com relação às perspectivas do BSC, tipo de indicador ou a qual processo de PLM se refere determinado indicador de desempenho.

Por fim, os autores deste trabalho agradecem a Fundação de Amparo à Pesquisa do Estado de São Paulo (FAPESP) pelo apoio concedido para a realização deste trabalho.

\section{Nota}

Este artigo é resultado da dissertação de mestrado intitulada Proposta de um quadro referencial para o desenvolvimento de um sistema de medição de desempenho para a gestão do ciclo de vida de produtos.

\section{REFERÊNCIAS}

BANWET, D. K.; DESHMUKH, S. G. Balanced scorecard for performance evaluation of R \& D organization : A conceptual model. Journal of Scientific \& Industrial Research, v. 65, p. 879-882, nov. 2006.

BIOLCHINI, J.; MIAN, P.; NATALI, A.; CONTE, T.; TRAVASSOS, G. Scientific research ontology to support systematic review in software engineering. Advanced Engineering Informatics, v. 21, n. 2, p. 133-151, 2007.

CHAN, A. Using an effective metrics program to support business objectives. In: K. Kahn; The PDMA handbook of new product development. 2 ed. Hoboken: John Wiley and Sons, 2004. Cap. 29, p.445-454.

CHEN, C.; YEH, T.; YANG, C. Performance measurement for new product development: a model based on total costs. International Journal of Production Research, v. 44, n. 21, p. 4631-4648, 2006.

CHIESA, V.; FRATTINI, F. Exploring the differences in performance measurement between research and development: evidence from a multiple case study. R\&D Management, v. 37, n. 4, p. 283-301, 2007.

CHIESA, V.; FRATTINI, F.; LAZZAROTTI, V.; MANZINI, R. How do measurement objectives influence the R\&D performance measurement system design?: Evidence from a multiple case study. Management Research News, v. 30, n. 3, p. 187-202, 2007.

. Designing a performance measurement system for the research activities: A reference framework and an empirical study. Journal of Engineering and Technology Management, v. 25, n. 3, p. 213-226, 2008. 
. Performance measurement of research and development activities.

European Journal of Innovation Management, v. 12, n. 1, p. 25-61, 2009a.

. Performance measurement in R\&D: Exploring the interplay between measurement objectives, dimensions of performance and contextual factors. R\&D Management, v. 39, n. 5, p. 488-519, 2009b.

CIMDATA. Product Lifecycle Managemente (PLM) Definition. Disponível em: <http://www.cimdata.com/plm/definition.html . Acesso em: 16 outubro 2010.

DRIVA, H.; PAWAR, K. S.; MENON, U. Measuring product development performance in manufacturing organizations. International Journal of Production Economics, v. 63, n. 2, p. 147-159, 2000.

FELDHUSEN, J.; BUNGERT, F. Reference models: a key enabler for multi-life products. In: International Conference on Product Lifecycle Management. Anais.... p.403 - 412. Geneve: Inderscience Enterprises Limited, 2007.

FRANCO-SANTOS, M. et al. Towards a definition of a businessperformance measurement system. International Journal of Operations and Production Management, v. 27, n. 8, p. 784-801, 2007.

GODENER, A.; SODERQUIST, K. E. Use and impact of performance measurement results in R\&D and NPD: an exploratory study. R\&D Management, v. 34, n. 2, p. 191-219, 2004.

GRIEVES, M. Product Lifecycle Management: Driving the next generation of lean thinking, 1 ed. New York: McGraw-Hill, 2006. 319 p.

HAMERI, A.; NIHTILÄ, J. Computerized product process: Measurement and continuous improvement. Research in Engineering Design, v. 10, n. 3, p. 166-177, 1998.

HAMMER, M.; CHAMPY, J. Reengineering the Corporation: A Manifesto for Business Revolution. London: Nicholas Brealey. 2001. 257 p.

KERSSENS-VAN DRONGELEN, I. C.; BILDERBEEK, J. R \& D performance measurement: more than choosing a set of metrics. R\&D Management, v. 29, n. 1, p. 35-46, 1999.

KERSSENS-VAN DRONGELEN, I. C.; COOK, A. Design principles for the development of measurement systems for research and development processes. R\&D Management, v. 27, n. 4, p. 345-357, 1997.

KITCHENHAM, B. Guidelines for performing systematic literature reviews in software engineering, Technical Report - Department of Computer Science, University of Durham, Durham, 2007. 
LOCH, C. H.; TAPPER, U. A. Implementing a strategy-driven performance measurement system for an applied research group. Journal of Product Innovation Management, v. 19, n. 3, p. 185-198, 2002.

MA, Y.; FUH, J. Product lifecycle modelling, analysis and management. Computers in Industry, v. 59, n. 2-3, p. 107-109, 2008.

MARTINS, R. Sistemas de medição de desempenho: um modelo para estruturação do uso. Tese (Doutorado) - Escola Politécnica, Universidade de São Paulo, São Paulo, 1998.

. The use of performance measurement information as a driver in designing a performance measurement system. In: NEELY, A.; WALTERS, A.; AUSTIN, R. performance measurement and management: research and action. Proceedings of the Third Performance Measurement and Management Conference, 2002, Performance Measurement Association, Boston, MA (USA), July 17-19, 2002, pp. 371-378.

MATSOKIS, A.; KIRITSIS, D. An ontology-based approach for Product Lifecycle Management. Computers in Industry, 2010. In press.

NEELY, A. Measuring business performance. 1 ed. London: The Economist Newspaper and Profile Books, 1998. 208 p.

NEELY, A., GREGORY, M., PLATTS, K. Performance measurement system design: A literature review and research agenda. International Journal of Operations and Production Management, v. 25, p. 1228-1263, 2005.

O'DONNELL, F.; DUFFY, A. Modelling design development performance. International Journal of Operations \& Production Management, v. 22, n. 11, p. 1198-1221, 2002.

OJANEN, V.; VUOLA, O. Coping with the multiple dimensions of R\&D performance analysis. International Journal of Technology Management, v. 33, n. 2/3, p. 279290, 2006.

PAWAR, K. S.; DRIVA, H. Performance measurement for product design and development in a manufacturing environment. International Journal of Production Economics, v. 60-61, p. 61-68, 1999.

PILLAI, A. S.; JOSHI, A.; RAO, K. S. Performance measurement of R\&D projects in a multi-project, concurrent engineering environment. International Journal of Project Management, v. 20, n. 2, p. 12, 2002.

RADNOR, Z. J., BARNES, D. Historical analysis of performance measurement and management in operations management. International Journal of Productivity and Performance Management, v. 56, , n.5/6, p. 384-396, 2007. 
REBITZER, G. et al. Life cycle assessment Part 1: Framework, goal and scope definition, inventory analysis, and applications. Environment International, v. 30, n. 5, p. 701-720, 2004.

ROGERS, H.; GHAURI, P.; PAWAR, K. S. Measuring international NPD projects: An evaluation process. Journal of Business and Industrial Marketing, v. 20, n. 2, p. 79-87, 2005.

SAAKSVUORI, A.; IMMONEN, A. Product lifecycle management. 3 ed. Berlim: Springer Verlag, 2003. 253 p.

SANDSTRÖM, J.; TOIVANEN, J. The problem of managing product development engineers: Can the balanced scorecard be an answer? International Journal of Production Economics, v. 78, n. 1, p. 79-90, 2002.

STARK, J. Product Lifecycle Management: 21st century paradigm for product realisation. p.441. London: Springer, 2006.

TATIKONDA, M. V. Product development performance measurement. In: Loch, C.; Kavadias, S.; Handbook of new product development management. 1 ed. Oxford: Elsevier, 2008. Cap. 8, p. 199-215.

THIMM, G.; LEE, S. G.; MA, Y. Towards unified modelling of product life-cycles. Computers in Industry, v. 57, n. 4, p. 331-341, 2006.

TRANFIELD, D.; DEYER, D.; SMART, P. Towards a Methodology for Developing Evidence-Informed Management Knowledge by Means of Systematic Review.

British Journal of Management, v.14, n.3, p.207-202. 2003.

XIAO, S.; XUDONG, C.; LI, Z.; GUANGHONG, G. Modeling framework for product lifecycle information. Simulation Modelling Practice and Theory, 2009. In Press.

YEH, T.; PAI, F.; YANG, C. Performance improvement in new product development with effective tools and techniques adoption for high-tech industries. Quality and Quantity, v. 44, n. 1, p. 131-152, 2010.

ZANCUL, E. Gestão do Ciclo de Vida de Produtos: Seleção de sistemas PLM com Base em Modelos de Referência. 2009. Tese (Doutorado) - Escola de Engenharia de São Carlos, Universidade de São Paulo, São Carlos, 2009.

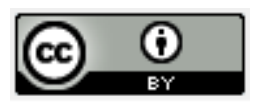

Artigo recebido em 03/11/2010 e aceito para publicação em 10/10/2011. 